URL: http://dergipark.ulakbim.gov.tr/ijhbs/index

Volume: 1, Issue: 1, Year: 2015

\title{
The Relationships between the Big Five Personality Traits and Academic Motivation Levels of Turkish University Students
}

\author{
İhsan Bozanoğlu \\ Kirlkkale University, Turkey \\ ihsan-06@yandex.com \\ Ahmet Sapanc1 \\ Düzce University, Turkey \\ ahmetsapanci@duzce.edu.tr
}

\begin{abstract}
The relationships between personality traits and motivation are significant for effective learning and teaching. The main purpose of this study is to determine the relationships between personality traits and motivation levels of Turkish university students. The specific purpose of the study is to determine which personality factor predicts academic motivation to what extent. For this purpose, Adjective Based Personality Scale (ABPT) developed by Bacanlı et al. (2009) was conducted on 353 (237 female, 116 male) students who study at state universities. ABPT was developed according to The Big Five Personality Traits and measures the five main factors of personality. Academic Motivation Scale was developed by Valerant et al. (1992) according to self-determination theory and consists of seven factors (Amotivation, External Regulation, Introjected Regulation, Identified Regulation, Intrinsic Motivation to Know, Intrinsic Motivation to Experience Stimulation and Intrinsic Motivation to Accomplish). Turkish adaptation was done by Karagüven in 2012. The results indicate that, all personality factors show significant relations with academic motivation. While conscientiousness has been shown to be positively and significantly correlated, neuroticism has been shown to be negatively and significantly correlated with academic motivation. In order to determine which personality factors predict academic motivation level stronger, data were analyzed by multiple regression analysis. The subcategories which form personality explain $16 \%$ of variance on the levels of student motivation. When the significance tests of regression coefficients were examined, the neuroticism and conscientiousness factors of personality $(\mathrm{p}<0,05)$ were found to be significant predictors of academic motivation.
\end{abstract}

Keywords: Big Five Personality Traits, academic motivation, Turkish university students

\section{Introduction}

Individuals differ based on types of personality and of motivation. Detection of these differences between individuals gives important clues regarding how education environments must be organized. Personality is an important source of difference that determines how the individual will respond to new information and new circumstances he/she encounters. For this reason, numerous perspectives and theories have been developed to explain personality and a classification (taxonomy) that would comprise personality structure has tried to be formed.

Gordon Allport and Henry Odbert created the first dictionary-like comprehensive list of characteristics related to personality. Thousands of words that define those characteristics had been obtained with years long studies. Later, in 1940s, Cattell acquired this list of adjectives created by Allport and Odbert and applied factor analysis, and created a model composed of 16 factors (Taymur and Türkçapar, 2012:158). Different researchers found evidence supporting 
five dimensions of personality by using different personality data (McCrae and John, 1992). Five-factor personality model is a hierarchical organization of the personality traits based on the dimensions of extroversion, agreeableness, conscientiousness, emotional instability (neuroticism), and openness to experience.

Extroverted individuals come to the fore with their social characteristics and boldness whereas introverted ones do not generally show these characteristics (John and Srivastava, 1999:60). "Introverted people are not cold but timid, not observant but independent, not numb but slow paced" (Costa; McCrae, 1992). Individuals who get a high score from the dimension of agreeableness express desired traits such as helpfulness, reliability, tolerance, whereas those who have a lower score from the mentioned dimension are observed to doubt others' behavior and express maladaptive and hostile attitude (Costa and McCrae, 1999, John and Srivastava, 1999:60). Conscientiousness indicates the degree of control and discipline we have over our behavior. The people at the highest edge of this dimension are organized, determined, and act in line with a plan. The ones at the lowest edge are easily distracted and have difficulty regarding self-control and what to focus on. The dimension of neuroticism places people at a point between personal harmony or emotional stability in contrast to maladaptiveness and emotional imbalance. Individuals with a high score in the dimension of neuroticism experience emotional imbalance and sadness, fear, guilt, anger, shame, and hate. Individuals with a high score from the dimension of openness to experience / development have creative ideas, are curious and aesthetical, have wider imagination, are independent, liberal, fond of change, have a broad range of interests, and excited (John and Srivastava, 1999:60).

Theory of self-determination is a theory that explains both personality and motivation. SDT generally investigates the reasons that lie beneath our behavior. The question of WHY is important in the theory and three basic psychological needs are suggested as the answer to that question; Autonomy, Competence and Relatedness (Deci \& Ryan, 1985; Ryan \& Deci, 2000). Need of autonomy is the characteristic that indicates the highest relation with the level of motivation. From the perspective of self-determination, motivation is ranked based on autonomy level between entirely internal and entirely external motivation. The third type of motivation, "amotivation", is described as discernable disconnection between actions and outcomes. They attribute achievement to luck or natural abilities and conclude that achievement is not earned through effort. Amotivated Individuals do not consider any relationship between effort and attainment of a reward (Deci \& Ryan, 1985).

Extrinsic motivation refers to engaging in an activity for instrumental reasons. Intrinsic motivation refers to engaging in an activity for its own sake, for the pleasure and satisfaction derived from participating in it (Ryan \& Deci, 2000). There are different types of extrinsic motivation that vary in terms of self-determination; external regulation, introjected regulation, identified regulation, and integrated regulation. These five behavioral regulations can be viewed as a continuum ranging from highly external to highly internal (Deci \& Ryan, 1985, 1987; Ryan \& Deci, 2000). In consideration of the correlations between motivation levels supported by different research (Ryan \& Connell; Vallerand et al., 1992, 1993), self-determined motivation level of people is acquired from the total of level scores with a special formula.

The relation between personality and motivation has always been of interest. Privately the relationship between academic motivation and personality traits is among the important questions to be answered in the arrangement of educational environments. The literature suggests that personality traits affect academic motivation/performance and can predict academic motivation and achievement (Costa \& McCrae, 1992; Komarraju \& Karau, 2005). Kaufman, Agars, and Lopez-Wagner (2008) found that students who were intrinsically motivated were extroverted, agreeable, conscientious, and open to new experiences. Phillips, Abraham, and Bond (2003) examined the relationship between personality and academic motivation and found that intrinsic motivation was positively related to conscientiousness, 
identified motivation was positively related to extroversion and conscientiousness and introjected motivation was positively related to neuroticism. Komarraju and her colleagues (Komarraju \& Karau, 2005; Komarraju, Karau, \& Schmeck, 2009) investigated the relationship between the Big Five personality traits and academic motivation and found several significant relationships between personality and motivation. Conscientious students were motivated by achievements while more neurotic students had high avoidance scores. They found that those who were intrinsically motivated tended to be conscientious and open to new experiences; those who were extrinsically motivated were conscientious, extroverted, and neurotic; and those who lacked motivation were disagreeable and lacked conscientiousness.

It is an issue of concern whether this relation observed at the levels of personality traits and motivation indicates the same characteristic in different cultures. The almost unchangeable structure of the Big five theory and the opinion that SDT is universal increase this concern even more. For this reason, this study has been designed to specify the relations between Five Factor Personality traits and academic motivation in Turkish university students.

\section{Method}

In this research, the dual relationship between personal traits and levels of motivation of university students has been examined and predictive correlational research model was used in order to determine the extent to which five basic factors that comprise personality predict the motivation scores specified according to self-determination theory.

\subsection{Sample}

Conducted with a total of 353 students in Kurıkkale University Faculty of Arts and Sciences in 2012-2013 academic years. Descriptive information on the sampling is given in Table 1.

Table 1. The sample characteristics in the study

\begin{tabular}{|c|c|c|c|c|c|c|c|}
\hline & & Female & Male & & & & \\
\hline \multirow{3}{*}{ Gender } & $\mathbf{n}$ & 237 & 116 & & & & \\
\hline & $\%$ & 67,1 & 32,9 & & & & \\
\hline & & $\mathbf{P h}$ & Ar & Soc & TLL & His & Per \\
\hline \multirow{3}{*}{ Department } & $\mathrm{n}$ & 115 & 40 & 108 & 49 & 20 & 18 \\
\hline & $\%$ & 32,6 & 11,3 & 30,6 & 13,9 & 5,7 & 5,1 \\
\hline & & 1 & 2 & 3 & 4 & & \\
\hline \multirow{2}{*}{ Grade } & $\mathbf{n}$ & 207 & 77 & 47 & 22 & & \\
\hline & $\%$ & 58,6 & 21,8 & 13,3 & 6,2 & & \\
\hline
\end{tabular}

Ph=Philosophy, Ar. $=$ Arabic, Soc $=$ Sociology,

$T L L=$ Turkish Language and Literature, His=History, Per= Persian

Of the students in the study group, $67 \%$ are females and $33 \%$ are males. Students from the departments of philosophy and sociology comprise $63 \%$ of the group whereas the examination of the participants based on grade indicates that $80 \%$ of the study group is comprised of 1 st and 2nd grade students.

\subsection{Instrument}

Personality Test Based on Adjectives (PTBA): PTBA developed by Bacanl1, İlhan and Aslan (2009) is a Likert type scale graded between 1-7 and comprised of 40 adjective pairs. PTBA consists of five dimensions namely extroversion, agreeableness, conscientiousness, neuroticism, and openness to experience. Five dimensions explain the $52.63 \%$ of the variance of PTBA. Cronbach Alpha Coefficients have been found to be .89 for Extroversion, .87 for Agreeableness, .88 for Conscientiousness, .73 for Neuroticism, and .80 for Openness to Experience. 
Academic Motivation Scale (AMS): "Academic Motivation Scale" developed by Vallerand et al.,(1992) and adapted to Turkish by Karagüven (2012) is composed of 28 items and seven subdimensions. Cronbach Alpha coefficients of this scale, which is a Likert type measurement tool graded between 1-7, is .79 for internal motivation to know, .74 for internal motivation to accomplish, .67 for internal motivation to experience stimulation, .79 for external motivation to organize, . 75 for external motivation to prove oneself, .73 for external motivation to be recognized, .83 for amotivation, and .87 for the entire scale.

\subsection{Data Analysis}

In order to examine the relations between the five factors comprising personality and motivation, Pearson Moment Product Correlation Coefficient; and to determine the impact of personal traits on motivation levels, multiple regression analysis was used. Total score was obtained from the Academic Motivation Scale developed according to Self-Determination Theory and comprised of seven sub-dimensions and the analyses were conducted based on this total score. During the process of obtaining total score from seven sub-dimensions, SelfDetermination Index (SDI) that is suggested by the authors (Vallerand\& Rousseau, 2001) who developed the original scale was used.

\section{Findings}

Relations between the five factors comprise personality and motivation are given in Table 2 .

Table 2: Relations between Personality and Motivation $(\mathbf{N}=353)$

\begin{tabular}{lllllll}
\hline 1 & 2 & 3 & 4 & 5 & 6 \\
\hline
\end{tabular}

\section{Conscientiousness}

2.Openness to Experience, $587^{* *}$

\begin{tabular}{|c|c|c|c|c|c|}
\hline 3. Extroversion &, $733^{* *}$ &, $491^{* *}$ & & & \\
\hline 4. Agreeableness &, $568^{* *}$ &, $703^{* *}$ &, $548^{* *}$ & & \\
\hline 5. Neuroticism &,$- 586^{* *}$ &,$- 573^{* *}$ &,$- 458^{* *}$ &,$- 391^{* *}$ & \\
\hline 6. Motivation &, $346^{* *}$ & $326^{* *}$ & $276^{* *}$ &, $259^{* *}$ &,$- 330^{* *}$ \\
\hline
\end{tabular}

$* * \mathrm{p}<.01$

In examination of Table 2, motivation and personality are observed to be positively and significantly related among sub-dimensions of conscientiousness $(\mathrm{r}=.35, \mathrm{p}<.01)$, openness to experience $(\mathrm{r}=.33, \mathrm{p}<.01)$, extroversion $(\mathrm{r}=.28, \mathrm{p}<.01)$, and agreeableness $(\mathrm{r}=.26, \mathrm{p}<.01)$ whereas there is a negative and significant relation between neuroticism and motivation $(r=.-33$, $\mathrm{p}<.01)$. According to this, significant relations $(\mathrm{p}<.01)$ between all dimensions of personality and motivation have been found

Table3: Multiple Regression Analysis Results on the Prediction of Motivation

\begin{tabular}{lccccccc}
\hline Variable & $\mathbf{B}$ & $\mathbf{S E}$ & $\boldsymbol{\beta}$ & $\mathbf{t}$ & $\mathbf{p}$ & Dual r & Partial r \\
\hline Constant & 4,017 & 1,57 & & & & & \\
Conscientiousness &, 524 &, 263 &, 165 & 1,996 &, 047 &, 346 &, 107 \\
Neuroticism &,- 523 &, 234 &,- 146 & $-2,230$ &, 026 &,- 330 &,- 119 \\
$\begin{array}{l}\text { Openness to } \\
\text { Experience }\end{array}$ &, 443 &, 264 &, 132 & 1,677 &, 094 &, 326 &, 090 \\
Extroversion &, 070 &, 252 &, 021 &, 277 &, 782 &, 276 &, 015 \\
Agreeableness &, 014 &, 256 &, 004 &, 054 &, 957 &, 259 &, 003 \\
\hline $\mathrm{R}=.394$ & $R^{2}=.155$ & & & & & & \\
$F_{(5)}=12,75$ & $\mathrm{p}=0,000$ & & & & & & \\
\hline
\end{tabular}


According to the results of the multiple regression analysis conducted in order to predict the impact of personality traits of students on their motivation, a significant relation $\left(\mathrm{R}=.394, \mathrm{R}^{\wedge} 2=\right.$ $.155)$ between the sub-dimensions of personality and motivation $\left(F_{-}((5))=12,75, p=0,000\right)$. Sub-dimensions that comprise personality explain approximately $16 \%$ of the variance in the motivation level of the students. According to standardized regression coefficients, the order of relative importance of the five sub-dimensions that comprise personality on motivation has been found to be conscientiousness $(\beta=, 165)$, neuroticism $(\beta=, 146)$, openness to experience $(\beta=$ ,132), extroversion $(\beta=, 021)$, and agreeableness $(\beta=, 004)$. In examination of the significance tests of regression coefficients, only neuroticism $(p<0,05)$ and conscientiousness $(p<0,05)$ are observed to be significant predictors of motivation.

In consideration of the relations between predictor variables and motivation, correlation is observed with conscientiousness $(\mathrm{r}=, 346)$, [When the impact of other predictor variables are controlled $(\mathrm{r}=0,107)$ ], with neuroticism $(\mathrm{r}=,-330)$, [When the impact of other predictor variables are controlled $(\mathrm{r}=-0,119)]$, with openness to experience $(\mathrm{r}=326)$, [When the impact of other predictor variables are controlled $(\mathrm{r}=0,90)$ ], with extroversion $(\mathrm{r}=, 276)$, [When the impact of other predictor variables are controlled $(\mathrm{r}=0,15)$ ], with agreeableness $(\mathrm{r}=, 259)$, [When the impact of other predictor variables are controlled $(\mathrm{r}=0,03)]$.

\section{Discussion and Conclusion}

In this study, the relation between personality traits and motivation levels of university students has been analyzed and the extent to which the five basic factors that comprise personality predict the motivation scores determined based on self-determination theory has tried to be specified.

According to the results of the research, there are significant $(\mathrm{p}<.01)$ relations between all dimensions of personality and motivation. Based on this, motivation and personality are observed to be positively and significantly related among sub-dimensions of conscientiousness $(\mathrm{r}=.35, \mathrm{p}<.01)$, openness to experience $(\mathrm{r}=.33, \mathrm{p}<.01)$, extroversion $(\mathrm{r}=.28, \mathrm{p}<.01)$, and agreeableness $(\mathrm{r}=.26, \mathrm{p}<.01)$ whereas there is a negative and significant relation between neuroticism and motivation $(\mathrm{r}=.-33, \mathrm{p}<.01)$. These results are similar to the results of the research conducted by Muller, Palekcic, Beck and Wanninger (2006) named personality, motives, and learning environment as the predictors of self-determined learning motivation. In the study of Muller, Palekcic, Beck and Wanninger (2006), a positive significant relation between SDI and conscientiousness, extroversion, agreeableness, and openness to experience was found whereas a negative significant relation was found between neuroticism and SDI. According to the results of the multiple regression analysis conducted in order to predict the impact of personality traits of the students on their motivation levels, a significant relation $(\mathrm{R}=$ $\left..394, \mathrm{R}^{\wedge} 2=.155\right)$ between the sub-dimensions of personality and motivation $\left(\mathrm{F}_{-}((5))=12,75, \mathrm{p}=\right.$ $0,000)$. Sub-dimensions that comprise personality explain approximately $16 \%$ of the variance in the motivation level of the students. According to standardized regression coefficients, the order of relative importance of the five sub-dimensions that comprise personality on motivation has been found to be conscientiousness $(\beta=, 165)$, neuroticism $(\beta=, 146)$, openness to experience $(\beta=, 132)$, extroversion $(\beta=, 021)$, and agreeableness $(\beta=, 004)$. In examination of the significance tests of regression coefficients, only neuroticism $(p<0,05)$ and conscientiousness $(\mathrm{p}<0,05)$ are observed to be significant predictors of motivation. These results are in compliance with the findings of Muller, Palekcic, Beck and Wanninger (2006) according to which the five factor personality traits explain $28,4 \%$ of the variance in self-determination variance. Similarly, there are parallelisms between the results obtained here and that of another important research in the literature (Kaufman,Agars, and Lopez-Wagner 2008;Komarraju \& Karau, 2005; Komarraju, Karau, \& Schmeck, 2009; Phillips, Abraham, and Bond 2003). 
This study was conducted on Turkish university students and self-determined motivation index was used in measuring motivation. In the following studies, a wider sampling group can be used and sub-factors of motivation and personality traits can be examined in more detail. The findings to be obtained will provide important information for both researchers and implementers.

\section{References}

Bacanl, H., İlhan,T. \& Aslan S. (2009). Development of a personality scale based on five factor: personality test based on adjectives (PTBA). Turkish Education Sciences Journal, 7(2), 261-279

Burger, M. J. (2006). Personality. İstanbul: Kaknüs publications.

Costa, P. T. Jr., \& McCrae, R. R. (1992). NEO PI-R professional manual: Revised NEO PI-R and NEO-FFI. Florida, FL: Psychological Assessment Resources, Inc.

Deci, E. L., \& Ryan, R. M. (1985). Intrinsic motivation and self-determination in human behaviour. New York: Plenum Press.

Deci, E. L., \& Ryan, R. M. (1987). The support of autonomy and the control of behavior. Journal of Personality and Social Psychology, 53, 1024-1037.

John O. P.; Srivastava, S. ( 1999). The Big-Five Trait Taxonomy: History, Measurement, and Theoretical Perspectives. Handbook of personality: Theory and research (2nd ed.). New York: Guilford

Karagüven., M.H.Ü. (2012) Adaptation of academic motivation scale into Turkish. Education Sciences in Theory and Practice - Educational Sciences: Theory \& Practice - 12(4) • Autumn $\bullet 2599-2620$

Kaufman, J. C., Agars, M. D., \& Lopez-Wagner, M. C. (2008). The role of personality and motivation in predicting early college academic success in non-traditional students at a Hispanic-serving institution.Learning and Individual Differences, 18, 492-496.

Komarraju, M., \& Karau, S. J. (2005). The relationship between the bigfive personality traits and academic motivation. Personality and Individual Differences, 39,557-567

Komarraju, M., Karau, S., \& Schmeck, R. (2009). Role of the Big Five personality traits in predicting college students' academic motivation and achievement.Learning and Individual Differences, 19,47-52

Libert, R. (1990). Personality. New York: Brooks Cole Pub.

Luthans, F. (1992). Organizational Behaviour. New York: McGraw Hill

McCrae, R. R.; John O. P. (1999). An Introduction to the Five-Factor Model and Its Applications. Journal of Personality, Vol 60 Issue 2

McCrae, R.R. ve Costa, P.T. (1985). Updating norman's 'adequate taxonomy': intelligence and personality dimensions in natural languages and questionnaires. Journal of Personality and Social Psychology, Vol. 49, pp. 710-21.

Muller, F.H., Palekcic, M., Beck, M. ve Wanninger, S. (2006). Personality, motives and learning environment as predictors of self-determined learning motivation. Review of Psychology, 13(2), 75-86

Phillips, P., Abraham, C., \& Bond, R. (2003). Personality, cognition, and university students' examination performance.European Journal of Personality, 17, 435-448.

Ryan, R. M., \& Connell, J. P. (1989). Perceived locus of causality and internalization: Examining reasons for acting in two domains. Journal of Personality and Social Psychology, 57, 749-761

Ryan, R. M., \& Deci, E. L. (2000). Intrinsic and extrinsic motivations: Classic definitions and new directions.Contemporary Educational Psychology, 25,54-67.

Taymur,İ; Türkçapar M.H.(2012). Personality: Definition, Classification, and Assessment. Current Approaches in Psychiatry, 4(2):154-177 
Vallerand, R. J., Pelletier, L. G., Blais, M. R., Briere, N. M., Sene'cal, C., \& Vallie'res, E. (1992).The Academic Motivation Scale: A measure of intrinsic, extrinsic, and amotivation in education. Educational and Psychological Measurement, 52, 1003-1017.

Vallerand, R. J., Pelletier, L. G., Blais, M. R., Briere, N. M., Sene'cal, C., \& Vallie'res, E. (1993). On the assessment of intrinsic, extrinsic, and amotivation in education: Evidence on the concurrent and construct validity of the Academic Motivation Scale. Educational and Psychological Measurement, 53, 159-172

Vallerand, R.J.\& Rousseau, F. L.(2001). Intrinsic and extrinsic motivation in sport and exercise: A review using the hierarchical model of intrinsic and extrinsic motivation. In R. N. Singer, H. A. Hausenblas, \& C. M. Janelle (Eds.), Handbook of Sport Psychology (2nd ed., pp. 389-416). New York: John Wiley \& Sons. 